\title{
IMPROVING ADULT LITERACY IN NIGER THROUGH MOBILE CALLS TO TEACHERS
}

In Niger, one of the poorest countries in the world, 85 per cent of adults are unable to read or write, even in local languages. Adult education programmes can be a route to improving adult literacy rates, but non-governmental organisation (NGO) and government schemes are characterised with low enrolment, high dropout, and poor teacher attendance. In partnership with the Ministry of Education, Catholic Relief Services, the Sahel Group, and Tufts University, regular phone calls and motivational support were given to teachers to encourage and monitor attendance of adult education programmes between 2018 and 2019. The impact of this project directly led to improved reading and maths scores. Based on this evidence, the approach has been tested by the Ministry of Education in primary schools.

\section{THE CHALLENGE}

Despite significant investments of time and money by donors, governments, adult learners, and teachers, a majority of students who graduate from adult education programmes still struggle to reach a basic reading threshold, which is crucial for sustained learning.

For adults who have never attended school - or went to school but did not become fully literate - adult education programmes offered by NGOs and the Ministry of Education can be their only chance to learn. But such programmes can be costly. They require a significant time investment - typically three hours per day, five days per week - for the already very busy adult learners.

In addition, in sub-Saharan Africa teacher absenteeism in adult education programmes can be a major problem, particularly in remote rural areas. In prior
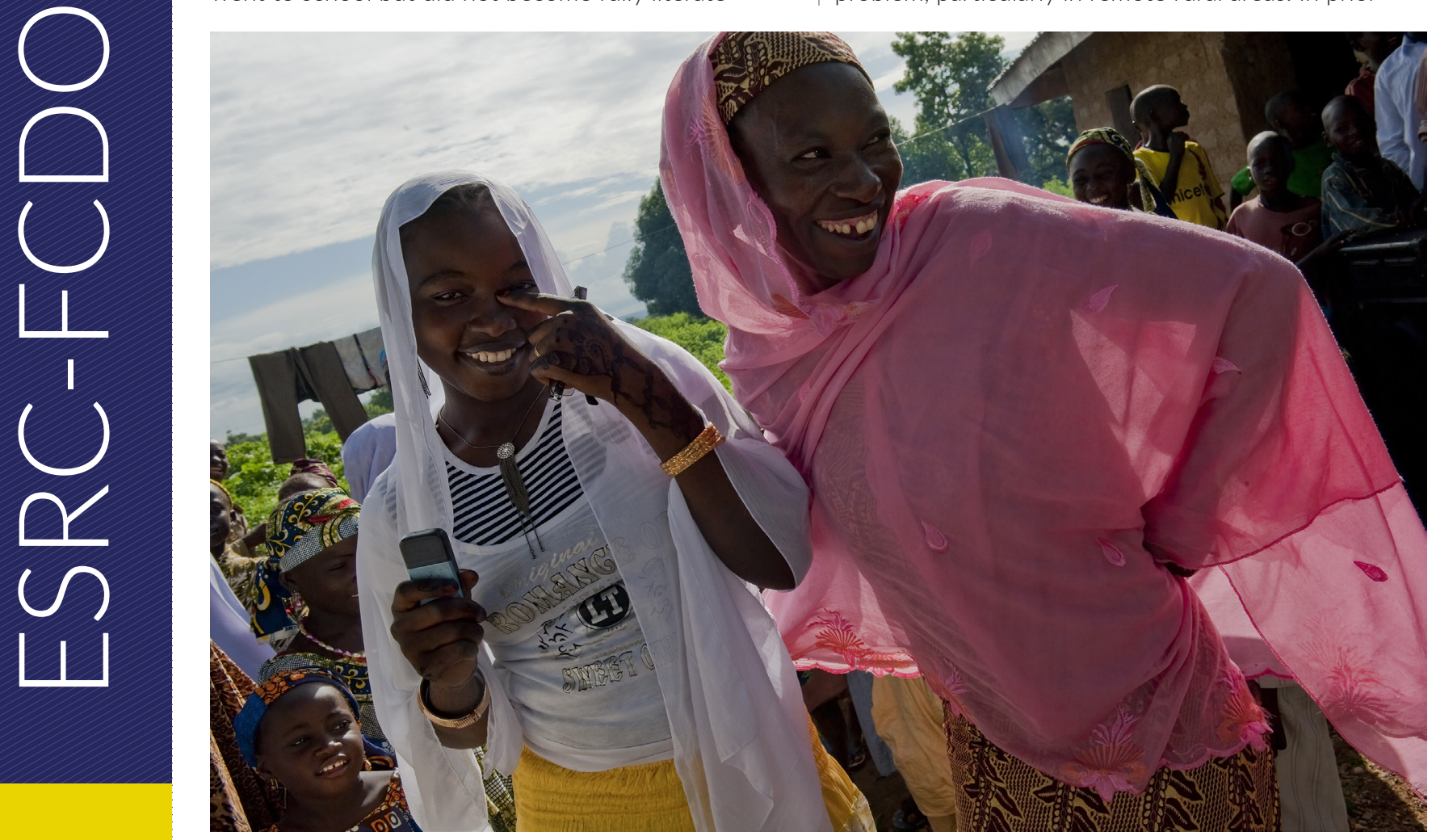

Photo: Women of Takalafiya-Lapai village. Credit: World Bank Photo Collection/Flickr under license CC BY-NC-ND 2.0 
work in Niger, adult education teachers typically missed one in three classes in a week. This may not be surprising, given that they work long hours, for low pay, in difficult conditions, and with little interaction, feedback, or encouragement from the Ministry or NGOs.

The evidence on the effectiveness of adult education programmes globally is very limited, and there is still considerable debate about how to improve adult learning in a cost-effective way. However, the widespread growth of mobile phone technology in remote rural areas in sub-Saharan Africa offers new opportunities to deliver adult education programmes.

\section{THE RESEARCH}

In the ESRC-FCDO-funded project 'Technology, Monitoring and Teacher Support in Niger', researchers used a randomised controlled trial to better understand how mobile phone technology could affect teachers' and adult learners' behaviour in an adult education programme implemented by the Ministry and an international NGO. The Sahel Group, an NGO, was engaged as a research partner.

Across two years, in 134 villages in two regions (Maradi and Zinder), the Sahel Group phoned teachers, students, and the village chief in half of the villages once a week and asked whether and for how long the classes were held. In the other villages, the classes were held as normal.

This simple approach of consistent mobile phone calls to students, teachers, and village leaders corresponded with an improvement across learning, teaching, and student behaviour in the villages that the Sahel Group contacted. Reading and maths scores improved by 12-15 per cent and the students that were phoned were also less likely to drop out of the programme and to sustain their learning. This was coupled with increased teacher attendance. The teachers who were phoned proved to be more likely to pass the Ministry's performance exam. Teachers understood that their work was being supervised, felt more valued, and therefore were more motivated.

As such, not only did the intervention improve learning outcomes for the adults involved in the programme - as measured by reading and maths tests - also it seems to have positively affected teachers' classroom preparation and effort. The cost-effective nature of the intervention means it could be replicated and scaled up in many different contexts.

\section{THE IMPACT}

Based on the evidence of the effectiveness of the intervention involving regular phone calls to teachers and adult students, the Nigerien Ministry of Education agreed to test out the approach in its primary schools. As in the adult education study, the Ministry implemented phone calls to teachers, the village chief, and parents. Yahaya Issa Brah, Pedagogical Advisor for the Ministry, said: 'The [Ministry's] pedagogical trainers also had more opportunities to supervise teachers' practices and monitor student learning. In summary, the behaviours and practices of all of the stakeholders changed favourably, thereby contributing to the better functioning of classes and, as a result, improving student learning.'

At an event for the ESRC-FCDO Raising Learning Outcomes in Education Systems Research programme, representatives from the UK Foreign, Commonwealth $\&$ Development Office (FCDO) also expressed interest that a similar scheme may work in Sierra Leone. This research has been applauded by the FCDO Chief Economist, Rachel Glennerster: 'What I love about Aker's [the author] work is it provides innovative, practical, scalable solutions to tough probs [sic] while helping us better understand the region. Adult literacy through cell phones, storage bags to prevent rotting cow peas [and] prevent farmers having to sell when prices are low.'

\section{FURTHER READING}

Aker, Jenny C. and Ksoll, Christopher J. (2020) 'Can ABC Lead to Sustained 123? The Medium-Term Effects of a Technology-Enhanced Adult Education Program', Economic Development and Cultural Change 68.3: 1081-102

Aker, Jenny C. and Ksoll, Christopher J. (2019) 'Call Me Educated: Evidence from a Mobile Phone Experiment in Niger', Economics of Education Review 72: 239-57

Aker, Jenny C.; Ksoll, Christopher and Lybbert, Travis J. (2012) 'Can Mobile Phones Improve Learning?

Evidence from a Field Experiment in Niger', American Economic Journal: Applied Economics 4.4: 94-120

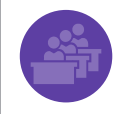

Technology, Monitoring and Teacher Support in Niger The research project was funded by ESRC-FCDO's Joint Fund for Poverty Alleviation Research. It was led by Tufts University in partnership with the Ministry of Education (Niger), Catholic Relief Services, and Sahel Group.

\section{THE IMPACT INITIATIVE}

\section{For International Development Research}

The Impact Initiative seeks to connect policymakers and practitioners with the world-class social science research supported by the ESRC-FCDO Strategic Partnership, maximising the uptake and impact of research from: (i) the Joint Fund for Poverty Alleviation Research, and (ii) the Raising Learning Outcomes in Education Systems Programme. We seek to identify synergies between these programmes and their grant holders, support them to exploit influencing and engagement opportunities, and facilitate mutual learning. The Impact Initiative is a collaboration between the Institute of Development Studies (IDS) and the University of Cambridge's Research for Equitable Access and Learning (REAL) Centre.

All content is available under the Open Government License v3.0, except where otherwise stated.

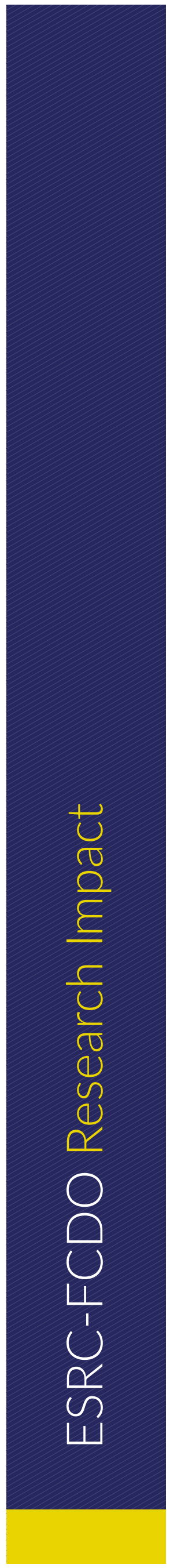

